\title{
New insight in pediatric dentistry: preventive dentistry in allergy management protocol
}

\author{
Seno Pradopo ${ }^{1}$ and Haryono Utomo ${ }^{2}$ \\ ${ }^{1}$ Department of Pediatric Dentistry \\ 2 Department of Oral Biology \\ Faculty of Dentistry Airlangga University \\ Surabaya - Indonesia
}

\begin{abstract}
The relationship between oral health and systemic diseases had been abundantly studied, however, mostly were related to adult such as cerebrovascular disease, cardiovascular disease, diabetes mellitus etc. Nevertheless, it was still uncommon that oral health also related to allergic disease. The field of pediatric dentistry is mostly related to preventive dentistry (i.e. prophylactic procedures, preventive orthodontic etc., but rarely related to preventive medicine such allergy prevention in children. Allergic diseases develop out of a close interaction between genetic predisposition and environmental triggers, and progress continuously since infancy regarding to the allergic march. Concerning to the partially developed immunity in children, children are more susceptible to infection and allergic diseases than adults. Unfortunately, infection and allergic diseases are interrelated; infection impaired allergy and vice versa. Poor oral health is closely related to infection; however, improving oral health is not included in allergy management protocol. In order to anticipate the future, dentist or especially pediatric dentist should be able to review about basic children immunity and oral mucosal immunity. Additionally, it is essential to explain to the parents and medical practitioners who are not familiar to this new paradigm. The objective of this study is to review articles related to children's oral health and allergic symptoms. Regarding to the successful oral management of allergic symptoms, the propensity that improving oral health could be included in children's allergy management protocol is likely.
\end{abstract}

Key words: pediatric dentistry, oral health, allergy management protocol

Correspondence: Seno Pradopo, c/o: Bagian Ilmu Kedokteran Gigi Anak, Fakultas Kedokteran Gigi Universitas Airlangga. Jln. Mayjend. Prof. Dr. Moestopo no. 47 Surabaya 60132, Indonesia. E-mail: pradopo_seno@yahoo.com; dhoetomo.indo.net. Telp. (031) 5030255.

\section{INTRODUCTION}

Allergic diseases develop out of a close interaction between genetic predisposition and environmental triggers. They are common in childhood, with at least $25 \%$ of children being affected by some atopic illness. In addition, the impacts of these disorders are disturbing regular activities such as absences children from schools, and parents from works, also increasing costs of health care and medications. Moreover, there are unwanted side effects from allergy medications that impaired the quality of life such as drowsiness (i.e. antihistamines) and suppression of growth (i.e. systemic glucorticoids). ${ }^{1}$ Nevertheless, with recent allergy management, food avoidance and immunotherapy, allergic diseases in children still continue until adult or even elderly.

The connection between oral health and general health had been studied by abundant literatures. ${ }^{2-4}$ Nevertheless, the relationship with allergy is still in controversy. Evidence-based cases revealed that improving oral health diminished urticaria, ${ }^{2}$ rhinitis, ${ }^{5}$ and sinusitis symptoms; $;{ }^{6,7}$ However, improving oral health is not included in allergy management protocol.
Chronic infections, either caused by virus or bacteria are able to stimulate hypothalamic-pituitary-adrenal axis (HPA axis), which released cortisol. Excessive cortisol act as an immunosuppressive agent which also facilitate shift to T-helper $2\left(\mathrm{~T}_{\mathrm{H}} 2\right)$ cytokines profile which related to allergy. ${ }^{8}$ In addition, bacteria and their toxins are able to trigger mast cells and basophil degranulation, and macrophages stimulation via complement system and toll-like receptors (TLRs). Inflammatory mediators released by these reactions may deteriorate allergic symptoms. ${ }^{9}$

General practitioner dentists and pediatric dentists may be the first health personnel who examine children's oral health. Consequently, they also have the responsibility to explain the importance of optimal oral health to general health, and also allergic diseases. In addition, it is mandatory to review basic medical sciences including microbiology and immunology to understand the connection between oral health and allergic diseases.

The purpose of this study is to conduct a literature study regarding the connection of oral health and allergic disease. Moreover, in the future, hopefully, improving oral health could be included in allergy management protocol; thus increase the contribution of pediatric dentistry in allergic 
prevention and obtaining optimal general health, thus also promotes optimal growth and development in children.

\section{Basic immune system}

There are two important part of immune system, the innate immunity and the acquired immunity. The simplest way to avoid infection is to prevent the microorganisms from gaining access to the body. The first line of defense which preventing from infection are skin, sweat, saliva, nasal secretions etc. Microbial and other foreign particles trapped within mucus secreted by the lining membranes are removed by mechanical stratagem such as coughing and sneezing. ${ }^{9}$

If penetration still occurs, two further innate defensive operations come into play, those are bactericidal enzymes and phagocytes (i.e. polymorphonuclear neutrophil and macrophages). Other parts of innate immunity are the complement system, natural killer and eosinophils. There are also other killing mechanisms which involved, for instance nitric oxide (NO), defensins and cathepsin G. ${ }^{9,10}$

For faster recognition and facilitate phagocytosis, antibodies were synthesized in part of the acquired immunity. There are several antibodies in the immune system that termed as immunoglobulin, the immunoglobulin M (IgM), IgG, IgA, IgD and IgE Furthermore, there are two kinds of immunity mechanisms involved, the cell-mediated immunity and humoral immunity. Antibodies are mostly produced in humoral immunity which needs the interactions of T-cells and B-cells lymphocytes. ${ }^{10}$

\section{Allergic diseases}

Allergic diseases are a group of ailments that share common pathogenic mechanisms including Ig-E mediated immediate hypersensitivity reactions to environmental allergens and a more fundamental pathogenic activation of $\mathrm{T}_{\mathrm{H}} 2$ immune responses. Included among these diseases are upper and lower allergic airway diseases (rhinitis, rhinosinusitis, asthma), ocular allergic diseases, eczema and food and drug allergies. They frequently cluster together in the same family and are transmitted vertically from generation to generation, consistent with a strong genetic component in disease pathogenesis. ${ }^{11}$

Allergic diseases are related to the subpopulation of T-cells so called the T-helper $2\left(\mathrm{~T}_{\mathrm{H}} 2\right)$ cells. These $\mathrm{T}_{\mathrm{H}} 2$ lymphocytes release cytokines upon stimulations that are interleukin 4 (IL-4) and IL-13 which able to induce antibody production by B-cells. Actually, in normal individuals, these cytokines stimulate immunoglobulin $\mathrm{M}(\operatorname{IgM})$ and IgG production which provide defense against bacteremia via opsonization. Nevertheless, in allergic individuals, these cytokines convert $\operatorname{IgM}$ and $\operatorname{IgG}$ to $\operatorname{IgE}$ through a mechanism so called "isotype switching". ${ }^{10}$ The increase of allergen-specific IgE in the circulation which then attached to the FceI receptors of immunocompetent cells such as mast cells and basophils make individuals more sensitive to allergens. ${ }^{1}$

\section{Immunoglobulin A and allergic disease}

Antigens, that are microorganisms and allergens before attaching to the mucosa are "blanket" by $\operatorname{IgA}$, which is the first immunoglobulin involved. ${ }^{12}$ Immunoglobulin A which also a constituent of saliva and termed as salivary $\operatorname{IgA}(\operatorname{sg} \mathrm{A})$ is a part of the secretory $\operatorname{IgA}(\operatorname{SIg} \mathrm{A})$ of the human body. ${ }^{9}$ Failure of $\operatorname{IgA}$ to protect antigens from adherence to the mucosa leads to further penetration of microorganisms and allergens into the mucosa and may lead to bacteremia. ${ }^{9,10}$ In children, $\operatorname{Ig} \mathrm{A}$ is the last immunoglobulin that reaches adult level. ${ }^{13}$

\section{The atopic/allergic march}

The allergic or atopic march refers to the natural history of allergic or atopic manifestations characterized by a typical sequence of clinical symptoms and conditions appearing during a certain age period and persisting over a number of years. Characteristic of the clinical signs is whereas others diminish or disappear completely. In general, the clinical features of atopic eczema occur first and precede the development of asthma and allergic rhinitis (Figure 1). ${ }^{14}$

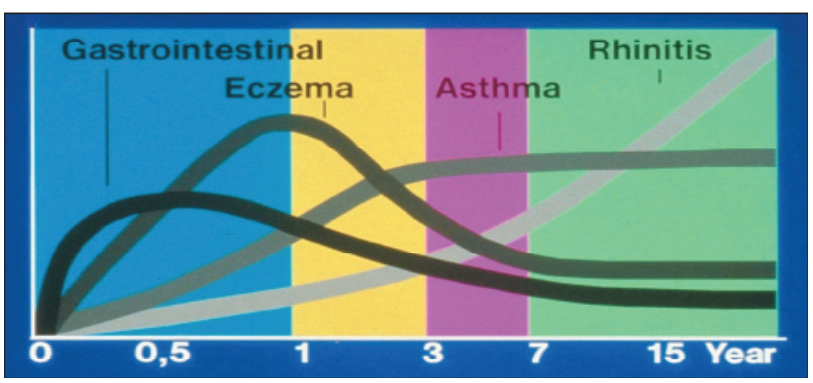

Figure 1. Incidence of atopic disease in early childhood.

The hygiene hypothesis and contra hygiene hypothesis

Hygiene hypothesis was introduced by DP Strachan in $1989,{ }^{15}$ it stated that cleanliness make people more allergic; it was based on his epidemiological study that children who lived in rural area were more allergic resistant. This was resulted from abundant infection since childhood which exposed to these children. Consequently, there was a tendency to shift into $\mathrm{T}_{\mathrm{H}} 1$ cytokines profile that was not related to allergy. ${ }^{15,16}$ On the opposite, Renz and Henz; and Prescott, showed that low dose of infections which involved lipopolysaccharides (LPS) may lead to the persistence of allergy. ${ }^{15-18}$

\section{Balance of the TH1/TH2 immune system}

Naturally, infants were born with the $\mathrm{T}_{\mathrm{H}} 2$ type; in nonatopic infant, it gradually shift to $\mathrm{T}_{\mathrm{H}} 1$ type thorough time upon exposed to environmental allergens; whereas, atopic infant has a further increase of $\mathrm{T}_{\mathrm{H}} 2$ cells that were potentially primed in utero by transplacental exposure to allergens. ${ }^{1}$ However, according to Prescott, the influence of inductive infection toward the $\mathrm{T}_{\mathrm{H}} 1$ immune system could only happened if it occurred in the early event of 
life, that was before 18 months of life. ${ }^{18}$ Other literatures stated that not only the $\mathrm{T}_{\mathrm{H}} 1 / \mathrm{T}_{\mathrm{H}} 2$ balance leads to allergic development, instead, the $\mathrm{T}_{\mathrm{H}} 2$ cells which release tumor growth factor $\beta$ (TGF $\beta$ ) were responsible for the regulatory or balancing system. ${ }^{15,17}$

\section{Infection and allergy}

Bacterial LPS from Gram negative bacteria is not the only microbial component that can act as an immunomodulator. Polymorphism in the toll receptor 2 (TLR-2) promoter has been associated with reduced allergic sensitization, asthma and hay fever. ${ }^{16,19}$ TLR-2 recognize peptidoglycans primarily produced by gram-positive bacteria, lipoprotein and zymosan, which is a component of yeast. Furthermore, the level of muramic acid, a major component of peptidoglycan that can be considered a marker for exposure to Gram-positive bacteria, was inversely correlated with wheezing and asthma. ${ }^{15}$

\section{Principles of treatment of allergic disease}

Basic principles of the treatment of allergic disease or allergy management protocol include: a) environment control measures (i.e. dust, smoking); b) pharmacologic therapy (i.e. adrenergic agents, antihistamines, glucocorticoids); c) allergen immunotherapy and d) food avoidance (i.e. peanut, cow's, milk eggs, fish, chocolate, fruits). ${ }^{1,11}$

The connection between oral health, systemic diseases and allergy

There were abundant literatures related to systemic infection which originated from periodontal or pulpal infections. Cerebrovascular and cardiovascular diseases were the most renowned; others are diabetes mellitus and pregnancy problems. ${ }^{2-4}$ Nevertheless, there were only several studies which related to allergy and controversial. Most literatures were epidemiological studies and concluded that allergic patients (i.e. rhinitis, asthma) had poor oral health; ${ }^{20}$ another allergic case reported were urticaria and sinusitis. ${ }^{2}$ It was interesting that according to Friedrich et al., periodontitis made people allergy-resistant, which coincidence with the hygiene hypothesis. ${ }^{21}$

\section{The connection between poor oral health and allergy in children}

Since 1990, the evidence-based medicine (EBM) had been popularized and facilitates clinicians to conduct their own researches. It also seeks to empower clinicians so they can develop independent views regarding medical claims and controversies. ${ }^{22}$ Concerning to EBM, it had been revealed that oral plaque control therapy in allergic rhinitis children resulted in disappearing of the symptoms. ${ }^{5}$ Evidence-based cases related to sinusitis in children also successfully treated with dental procedures. ${ }^{7}$

\section{Oral microbiota in children}

According to Tanner et al., since birth, abundant microorganisms colonized in oral mucosa and tongue of children. Even after their sixth months of life Gram negative bacteria such as prevotella intermedia and porphyromonas gingivalis could be found in children. ${ }^{22}$ Furthermore, according to Socransky, dental plaque may contain 100 million to one billion bacteria in a single tooth. One of harmful effect of dental plaque is droplet infections which cause respiratory infections. 5

\section{DISCUSSION}

Allergic diseases are common in children and the prevalence is increasing, especially in Western societies. Environmental factors such as exposure to allergens and pollution play an important role in the development and sustenance of allergic diseases. However, the development of allergic diseases is also governed by strong genetic influences, when one of both parents have history of allergic diseases, the incidence climbing up to $40 \%$ and $70 \% .^{11}$

Additionally, children with allergy have several disadvantageous characteristics against infection. First, allergic children have the predisposition of IgA deficiency, $\operatorname{IgA}$ is essential for the first body defense mechanism. Second, they have a $\mathrm{T}_{\mathrm{H}} 2$ cytokines profiles that inactivate macrophages which needed for phagocytosis. Third, they usually consumed antihistamines which diminished histamine concentration; actually histamine is essential for vasodilatation of blood vessels which intended for recruitment of white blood cells into the area of infection. Others are food avoidance which mostly consisted of proteins (i.e. eggs, fish and cow's milk) that are essential for immunoglobulin synthesis and children's growth and development. ${ }^{1,9,24}$

Moreover, infections, especially low grade infections, may enhance the allergic symptoms. Product of inflammation, such as bradykinins and prostaglandins were able to increase the sensitivity of nerve which involved in allergic mechanism, such as the maxillary nerve (CN V2) in rhinitis and sinusitis. ${ }^{25}$ Moreover, according to literatures, tumor necrosis factor $-\alpha(\mathrm{TNF} \alpha)$ may loosen the epithelial junction which facilitates penetrations of antigens or allergens into the mucosa. ${ }^{26,27}$ Thus, allergic patient may become more sensitive to allergens.

It was also in concordance with Zeldin et al. ${ }^{16}$ who stated that effective TLRs, thus an effective mechanism against infection reduced asthma symptoms. The possible correlation between infection and other allergy symptoms could be extrapolated via the development of allergy concept which related to the atopic march. For this reason, the idea to reduce infection for suppressing allergic symptoms is plausible.

Allergic patient may be more susceptible to infection, especially oral infection, because of their certain characteristics i.e. ineffective $\mathrm{T}_{\mathrm{H}} 3$ cytokine profiles ${ }^{15}$ which responsible to decrease $\mathrm{SIgA}$ and $\operatorname{sIg} \mathrm{A}$ and the conversion of $\operatorname{IgM}$ and $\operatorname{IgG}$ to $\operatorname{IgE}$ (isotype switching), which reduced opsonization effectivity of immunoglobulin; and macrophage inactivation by $\mathrm{T}_{\mathrm{H}} 2$ cytokines, its activity 
actually needed for phagocytosis. In children, it becomes more pronounced since children reached their IgM and IgG adult level after 5 years old, whether $\operatorname{IgA}$ is around $10 .{ }^{13}$

Allergic diseases consisted of symptoms ranging from mild (i.e. urticaria, rhinitis) to life-threatening (i.e. anaphylactic shock); whatsoever the characteristic of the symptoms it could affect the quality of life. Additionally, it also affect the socioeconomic status of the patients and their parents. Allergic children are supposed to be less confidence because they are prohibited to do heavy sports, eating their children's favorite food (i.e. ice cream, food made from poultry products etc). Since allergic diseases may continue for a long time. Allergic diseases mostly had comorbidities, such as asthma with rhinitis and sinusitis; it is interesting that treatment between comorbidities was able to cure each other. ${ }^{28}$

Infections which elicited by bacteria and their toxins are able to trigger mast cells degranulation which release an array of mediators (i.e. histamine, prostaglandins, leukotrienes), cytokines (i.e. TNF- $\alpha$, IL-3, IL-4, IL-5, IL-13), enzymes and chemotactic factor for granulocytes; subsequently it leads to an influx of plasma $\operatorname{IgG}$, complements and neutrophils. Infections also triggers degranulation of basophils (white blood cells which mimicking the characteristics of mast cells); moreover, it also responsible for macrophages stimulation that release IL-1, TNF- $\alpha$. Reactions of these immunocompetent cells release an array of mediators and enzymes that if present in excessive amount are harmful for allergic patient. ${ }^{9,29}$

According to Socransky, droplets infection originated from dental plaque may lead to respiratory infections. ${ }^{30}$ Therefore, it is not surprising that children have chronic cough, which actually is a kind of defense mechanism. Since it has recurrent and frequent episodes, this cough symptom is blamed to be caused by allergy. As the result, chronic cough may also be originated from droplets infection that adheres to the respiratory tract. Since cough is a part of innate immunity, ${ }^{9}$ it become natural that chronic droplet infections, thus continuing irritations may stimulate persistent cough.

The possible connection between oral health and allergic symptoms should also happen to chronic rhinitis or sinusitis. According to Boyd, inflammation of the same distribution of nerve, that was the maxillary nerve, which caused nasal congestion may be originated from the inflammation in other maxillary nerve (CN V2) distribution. ${ }^{25}$ The possibility of the other distribution of maxillary nerve involvement in rhinitis and sinusitis had been revealed by several literatures. In those studies and some case reports were discussed about the neurogenic switching mechanism. ${ }^{6,7,31}$

Through neurogenic switching mechanism, local inflammation was able to propagate to a distant organ (i.e. food allergy, sinusitis, asthma, urticaria) via mast cell-nerve interactions. ${ }^{31}$ Moreover, this mechanism could be initiated from oral inflammation i.e. gingivitis. ${ }^{32}$ Referred to these literatures, propagation of oral inflammation to distant organs is likely. It was interesting that there were evidencebased cases which showed that removal of plaque and improving oral health were able to diminished rhinitis and sinusitis symptoms. ${ }^{5-7}$ According to these case reports, even though only preliminary studies; the idea how improving oral health may able to suppress allergic symptoms should be supported to be accepted in the dental and medical societies.

Food avoidance as a part of allergy management had several disadvantages for children growth and development. First, the prohibited food was essential for general health such as egg, milk, fruits. Even chocolate, which mostly harmful for asthmatic patients, had a beneficial content, that was the flavonoid, an anti-oxidant. Nevertheless, it was limited to the dark chocolate which contains $70 \%$ cocoa. According to literatures, flavonoids could be found alsoin fruits i.e. apple. ${ }^{33}$ Additionally, since immunoglobulins were made from proteins, food avoidance made allergic children more prone to infections. Consequently, according to above discussion, they became more allergic. Second, food avoidance may also disturb children's social life, i.e. they could not eat the same food with their friends in a birthday party.

In order to improve oral health which considered advantageous to allergic children, dental practitioners have to check up and clean teeth, tongue and other mucosal area regularly. This procedure is a part in pediatric preventive dentistry. In addition, microorganisms which also exist in dental plaque may also accumulate on the tongue since infancy. ${ }^{23}$ Consequently, removing dental plaque which attached on the teeth and tongue may prevent from bacteremia; thus preventing children from suffering more severe allergic symptoms. Dental health education (including tongue brushing) should also be taught to their parents for daily oral health care maintenance.

Taken together, it could be summarized that dental practitioner, especially who is interested in pediatric dentistry, should be aware about the possible connection between children's oral health and allergic symptoms, even though it was still in researches. For this reason, dental practitioner is suggested to improve their knowledge (i.e. basic immunology) in order to explain questions that may come to mind by patients, their parents or their physician. However, the collaboration with general practitioner, pediatrician, especially allergy experts, is mandatory. Furthermore, in order to receive the acceptance of this hypothesis by the medical society, evidence-based cases should be collected and reported, and collaborated researches with medical practitioners should be conducted.

Moreover, after less consumption of allergic medication which may cause drowsiness and uncomfortable feeling, children become more active and cheerful. Reduced allergic symptoms also stress-relieving, because children feel free to eat prohibited food, to play and to do many sports activities. Relief of stress is advantageous for allergic patients because it may shift the $\mathrm{T}_{\mathrm{H}} 2$ cytokine profile (the atopic type) to the $\mathrm{T}_{\mathrm{H}} 1$ (the non-atopic type). The conclusion are that pediatric 
dentistry, via the preventive dentistry procedure has the propensity to improve general health, especially in allergic prevention; and minimizing the need of food avoidance which is considered disadvantageous for promoting growth and development. Hopefully, in the future, after further researches pediatric dentistry could be included in allergy management protocol.

\section{REFERENCES}

1. Leung DYM. In: Behrman RE, Kliegman RM, Jenson HB, editors. Nelson textbook of pediatrics. $17^{\text {th }}$ ed. Philadelphia: Saunders; 2004. p. 743-77.

2. Li XJ, Kolltveit KM, Tronstad L, Olsen I. Systemic diseases caused by oral infection. Clin Microbiol Rev 2000; 13(4):547-58.

3. Lavigne SE. Your mouth-portal to your body. Probe 2004; 38(3):114-34.

4. Scannapieco FA. Periodontal inflammation: from gingivitis to systemic disease. Compendium 2004; 25(7):S17-S25.

5. Utomo H, Setijanto D. Apakah terapi pengendalian plak gigi dapat menurunkan keparahan rinitis alergika pada anak. Majalah Kedokteran Gigi (Dental Journal) 2005; 38(2):96-102.

6. Utomo H. Sensitization of sphenopalatine ganglion by periodontal inflammation: a possible etiology for sinusitis and headache in children. Majalah Kedokteran Gigi (Dental Journal) 2006; 39(2):63-71.

7. Utomo H, Pradopo S. A practical dental approach in children's rhinosinusitis management. Indonesian J Dent 2006; 13(3):133-6.

8. Padgett DA, Glaser R. How stress influence the immune response. Trends in Immunology 2003; 24:444-8.

9. Rabson A, Roitt IM, Delves PJ. Really essential medical immunology. $2^{\text {nd }}$ ed. Carlton: Blackwell Publishing; 2004. p. 8-10.

10. Abbas AK, Lichtman AH. Cellular and molecular immunology. $5^{\text {th }}$ ed. Philadelphia: Saunders; 2005. p. 34-35.

11. Chatila TA. In: Rudolph CD, Rudolph AM, editors. Rudolph's pediatric. $21^{\text {st }}$ ed. New York: McGraw-Hill; 2004. p. 809-11.

12. Pilette C, Durham SR, Vaerman JP, Sibille Y. Mucosal immunity in asthma and chronic obstructive pulmonary disease: a role for immunoglobulin A? Proc Am Thorac Soc 2004; 1:125-35.

13. McDade TW. Life history theory and the immune system: Steps toward a human ecological immunology. Yearbook of Physical Immunology 2003; 46:100-25.

14. Weinberg EG. The atopic march. Curr Allerg Clin Immunol 2005; 18(1):4-5.

15. Romagnani $\mathrm{S}$. The increased prevalence of allergy and the hygiene hypothesis: missing immune deviation, reduce immune suppression, or both? J Allergy Clin Immunol 2004; 112:352-63.
16. Zeldin DC, Eggleston P, Chapman M, Piedimonte G, Renz H, Peden D. How exposures to biologics influence the induction and incidence of asthma. Environ Health Perspect 2006 April; 114(4):620-6.

17. Renz H, Herz U. The bidirectional capacity of bacterial antigens to modulate allergy and asthma. Eur Resp J 2002; 19:158-71.

18. Prescott SL. Bacteria and the allergy epidemic: the culprits and the cure. Curr Allerg Clin Immunol 2004; 17(3):108-14.

19. Supajatura V, Ushio H, Nakao A, Akira S. Differential responses of mast cell Toll like receptors 2 and 4 in allergy and innate immunity. Clin Invest 2002; 109(10):1351-9.

20. Laurikainen K. Asthma and oral health: a clinical and epidemiological study. Academic dissertation. Tampere: Tampere University Press; 2002. p. 1-182.

21. Friedrich N, Volzke H, Schwahn C, Kramer A, Junger M, Schafer $\mathrm{T}$, et al. Inverse association between periodontitis and respiratory allergies. Clin Exp Allergy 2006; 36(4):495-502.

22. Del Mar, Glasziou P, Mayer D. Teaching evidence based medicine. BMJ 2004; 329:989-90.

23. Tanner ACR, Milgrom PM, Kent R. The microbiota or young children in tongue and tooth samples. J Dent Res 2002; 81(1):52-7.

24. Palmer CA, Boyd LD. Nutrition, diet and oral condition. In: Harris NO, Godoy FG, editors. Primary preventive dentistry. $6^{\text {th }}$ ed. New Jersey: Penson Prentice Hall; 2004. p. 449-64.

25. Boyd J. Pathophysiology of migraine and rationale for a targeted approach and prevention. Available online at URL http://www. migraineprevention.com/index/html. Accessed February 15, 2006.

26. Okeson JP. Bell's orofacial pain. $6^{\text {th }}$ ed. Carol Stream: Quintessence Pub; 2005. p. 262.

27. Go M, Kojima T, Takano K, Murata M, Ichimiya S, Tsubota T. Expression and function of tight junction in the crypt epithelium of human palatine tonsils. J Histochem Cytochem 2004; 52(12):1627-38.

28. Serrano C, Valero A, Picado C. Rhinitis and asthma: one airway, one disease. Arch Bronconeomol 2005; 41:569-78.

29. Walsh L J. Mast cells and oral inflammation. Crit Rev Oral Biol Med 2003; 14(3):188-98.

30. Socransky E. American Medical Network. Oral bacteria from gum disease can cause ailments elsewhere in body. Available at: URL http://www.dental.am. Accessed November 10, 2004.

31. Cady RK, Schreiber CP. Sinus headache or migraine. Neurology 2002; 58:S10-S14.

32. Lundy W, Linden R. Neuropeptides and neurogenic mechanism in oral and periodontal inflammation. Crit Rev Oral Biol 2004; 15(2):82-98.

33. Garcia V, Arts ICW, Sterne JAC, Thompson RL, Shaheen SO. Dietary intake of flavonoids and asthma in adults. Eur Respir J 2005; 26(3):449-52. 